\title{
UTILIZATION OF METALLURGICAL SOLID BY-PRODUCTS FOR THE DEVELOPMENT OF INORGANIC POLYMERIC CONSTRUCTION MATERIALS
}

\author{
I. GIANNOPOULOU \\ D. DIMAS \\ I. MARAGKOS \\ D. PANIAS*
}

Received: $11 / 09 / 08$

Accepted: 04/11/08

\author{
National Technical University of Athens \\ School of Mining and Metallurgical Engineering \\ Laboratory of Metallurgy \\ Iroon Polytechniou 9, 15780 Athens, Greece
}

*to whom all correspondence should be addressed: e-mail: panias@metal.ntua.gr

\begin{abstract}
This paper deals with the geopolymerization of the red mud generated in the primary aluminium production and the slag generated in the ferronickel production, in order to develop inorganic polymeric materials with advanced mechanical and physical properties. In particular, the effect of the main synthesis parameters of the inorganic polymeric materials on their mechanical strength and water absorption was investigated. Moreover, the structure of the inorganic polymeric materials was studied according to X-ray Diffraction analysis, Fourier Transform Infra Red spectroscopy and Scanning Electronic Microscopy. The inorganic polymeric materials produced by the geopolymerization of the red mud developed compressive strength up to $21 \mathrm{MPa}$ and presented water absorption lower than $3 \%$, while the geopolymerization of the ferronickel slag resulted in materials with compressive strength higher than $110 \mathrm{MPa}$ and extremely low water absorption (<1\%). According to these results, the developed materials may be viewed as alternatives in the industrial sectors of construction and building materials.
\end{abstract}

KEYWORDS: geopolymerization; geopolymers; red mud; ferronickel slag.

\section{INTRODUCTION}

Extractive metallurgy is strongly related to the generation of enormous quantities of solid wastes that cause severe contamination of the air, soil and surface- and ground-water bodies. According to the EC Directive 96/61/EC (European Commission, 1996) laid down for the management of industrial wastes and by-products, the recycling of industrial solid wastes and by-products, as well as their re-use as secondary raw materials, is strongly enhanced, in order to eliminate and/or prevent the environmental pollution, protect the human's health and preserve the natural resources.

In this direction, an extended research, aiming at the development of viable technologies for the utilization of industrial solid wastes and by-products in the production of useful materials, is performed during the last decades. Among the developed technologies, geopolymerization gains increasing attention as it achieves to turn numerous industrial by-products into addedvalue materials (Palomo et al., 1999; Van Deventer et al., 2002; Cheng and Chiu, 2003; Bakharev, 2005; Panias et al., 2007; Maragkos et al., 2008) and to offer possible technological solutions for the effective stabilization of hazardous wastes (Bankowski et al., 2004; Xu et al., 2006), as well as for the encapsulation of toxic and radioactive wastes (Van Jaarsveld et al., 1999), contributing significantly to the elimination and/or reduction of the environmental pollution.

Geopolymerization process is based on a heterogeneous chemical reaction that occurs between solid materials rich in alumino-silicate oxides and highly alkaline silicate solutions. The geopolymerization reaction is exothermic and takes place at atmospheric pressure and temperatures below $100{ }^{\circ} \mathrm{C}$ (Davidovits, 1999; Van Deventer et al., 2002). Under a complicate 
mechanism, this reaction results in the formation of durable and compact solid materials characterized by a specific three-dimensional polymeric structure. The produced materials comprise a family of novel inorganic polymeric materials, which are also called "geopolymers". The most proposed mechanisms for the geopolymerization process (Swanepoel and Strydom, 2002; Van Deventer et al., 2002) include the following four stages that proceed in parallel and thus, it is difficult to be distinguished: (i) $\mathrm{Si}$ and Al dissolution from the solid alumino-silicate materials in a strong alkaline aqueous solution, (ii) formation of oligomers (polynuclear hydroxy-complexes of silicon and aluminium) consisting of polymeric bonds of Si-O-Si and SiO-Al type, (iii) polycondensation of the oligomers to form a three-dimensional aluminosilicate framework (geopolymeric framework) comprising $\mathrm{SiO}_{4}$ and/or $\mathrm{AlO}_{4}$ tetrahedra linked alternately by sharing common oxygen ions and (iv) bonding of the non-dissolved solid particles into the geopolymeric framework and hardening of the whole system into a final solid polymeric material.

Geopolymers are amorphous to semi-crystalline materials and possess excellent physicochemical and mechanical properties, like low density, micro- or nano- porosity, negligible shrinkage, high mechanical strength, notable surface hardness, thermal stability, fire and chemical resistance (Davidovits, 1999; Palomo et al., 1999; Van Deventer et al., 2002; Cheng and Chiu, 2003; Maragkos et al., 2008). Due to these properties, geopolymers are viewed as alternatives for certain industrial applications in the areas of construction and building materials.

This paper aims at studying the geopolymerization of the red mud generated in the primary aluminium production and the slag generated in the ferronickel production, in order to develop novel inorganic polymeric materials for construction purposes. In particular, the main synthesis parameters affecting the mechanical strength and water absorption of the inorganic polymeric materials are investigated and the structure of the produced materials is studied according to X-ray Diffraction (XRD) analysis, Fourier Transform Infra Red (FTIR) spectroscopy and Scanning Electronic Microscopy (SEM), so as to confirm their specific polymeric structure.

\section{EXPERIMENTAL}

Table 1 presents the chemical analysis of the red mud (RM), ferronickel slag (FS) and metakaolin (MK) samples used in this research for the development of inorganic polymeric materials. Metakaolin was added in the red mud-based inorganic polymeric materials comprising $15 \%$ wt of the system solid phase. Given that red mud consists of slightly soluble aluminosilicate phases in alkaline environments, the addition of metakaolin provides initially the geopolymeric system with soluble Si and Al (Davidovits, 1999) that are essential for the aluminosilicate oligomers formation and consequently, for the progress of the whole geopolymerization process.

According to the X-ray diffraction analysis of these metallurgical by-products, red mud is a crystalline material (as also seen in section 3.2) that comprises mainly the mineralogical phases of hematite $\left[\mathrm{Fe}_{2} \mathrm{O}_{3}\right]$, diaspore $[\mathrm{AIO}(\mathrm{OH})]$, cancrinite $\left[\mathrm{Na}_{6} \mathrm{Ca}_{2} \mathrm{Al}_{6} \mathrm{Si}_{6} \mathrm{O}_{24}\left(\mathrm{CO}_{3}\right)_{2} \cdot 2 \mathrm{H}_{2} \mathrm{O}\right]$ and perovskite $\left[\mathrm{CaTiO}_{3}\right]$. Ferronickel slag is an amorphous material, in which the only occurred crystalline phase is attributed to magnetite $\left[\left(\mathrm{Fe}^{2+}, \mathrm{Mg}\right)\left(\mathrm{Fe}^{3+}, \mathrm{Al}, \mathrm{Cr}, \mathrm{Ti}\right)_{2} \mathrm{O}_{4}\right]$. Metakaolin is also an amorphous material, in which ilite is the major crystalline constitute.

Except for the aforementioned solid by-products, sodium hydroxide of analytical grade (Merck, anhydrous pellets), sodium silicate solution (Merck, $\mathrm{Na}_{2} \mathrm{O}: \mathrm{SiO}_{2}=3.4, \mathrm{Na}_{2} \mathrm{O}=7.5-$ $8.5 \%, \mathrm{SiO}_{2}=25.5-28.5 \%$ and $\mathrm{d}=1,346 \mathrm{~g} \mathrm{I}^{-1}$ ) and deionized water were used for the synthesis of the inorganic polymeric materials.

The inorganic polymeric materials were synthesized following the procedure described in

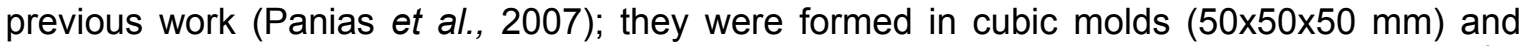
cured in a laboratory-scale oven for 72 hours, under atmospheric pressure, temperature $60{ }^{\circ} \mathrm{C}$ and relative humidity $70 \%$. The formed cubic specimens were kept in closed molds for the first six hours of the curing procedure. Thereinafter, they were de-molded and left in the oven until the curing procedure to be completed. After curing, the produced specimens were left for 
48 hours at ambient conditions for more hardening, before any test and analysis to be carried out.

Table 1. Chemical analysis of the red mud (RM), slag (FS) and metakaolin (MK) samples

\begin{tabular}{|c|c|c|c|c|c|c|c|c|c|c|}
\hline \multirow{3}{*}{ Sample } & \multicolumn{8}{|c|}{ Metal oxide } & \multirow{2}{*}{ L.o.I. } & \multirow{2}{*}{ Total } \\
\hline & $\mathrm{SiO}_{2}$ & $\mathrm{Al}_{2} \mathrm{O}_{3}$ & $\mathrm{Fe}_{2} \mathrm{O}_{3}$ & $\mathrm{CaO}$ & $\mathrm{K}_{2} \mathrm{O}$ & $\mathrm{Na}_{2} \mathrm{O}$ & $\mathrm{MgO}$ & $\mathrm{TiO}_{2}$ & & \\
\hline & \multicolumn{10}{|c|}{ mass, \% } \\
\hline RM & 7.36 & 20.61 & 41.43 & 8.92 & 0.05 & 0.43 & 0.25 & 10.28 & 9.91 & 99.24 \\
\hline FS & 38.50 & 10.11 & 39.42 & 5.97 & - & - & 5.20 & - & - & 99.20 \\
\hline MK & 52.66 & 40.98 & 1.83 & 0.18 & 1.18 & 0.56 & 0.34 & 1.43 & - & 99.16 \\
\hline
\end{tabular}

The structure of the produced inorganic polymeric materials was investigated according to the X-Ray Diffraction (XRD) analysis (Siemens-D 5000 / Cu Ka radiation, $\lambda=1.5418 \AA$, $40 \mathrm{kV}, 30$ $\mathrm{mA}$ ), Fourier Transform Infra Red (FTIR) spectroscopy (Perkin Elmer 880) and Scanning Electronic Microscopy (SEM) (JEOL 6380LV). The uniaxial compressive strength (UCS) of the produced materials was measured on a testing machine of the Structural Behavior Engineering Laboratories Inc. (MODEL PTL-10). Two samples of each synthesized material were tested with the average of measurements to be recorded as the result. Finally, water absorption measurements of the produced materials were performed based on EN 7711:2003 and ASTM C 67-03a standard tests.

\section{RESULTS AND DISCUSSION}

\subsection{Effect of the synthesis parameters on materials properties}

The solid materials used for the production of inorganic polymeric materials comprise the solid phase of the system, of which the aqueous phase consists of sodium hydroxide and sodium silicate solutions. The solid to liquid (S/L) ratio, as well as the sodium hydroxide and silicon concentrations in the aqueous phase of the system, are considered as the main synthesis parameters of the inorganic polymeric materials affecting their physical and mechanical properties (Palomo et al., 1999; Swanepoel and Strydom, 2002; Van Deventer et al., 2002; Cheng and Chiu, 2003; Panias et. al., 2007).

Figure 1 presents the compressive strength of the red mud/metakaolin- (G-RM) and the ferronickel slag- (G-FS) based inorganic polymeric materials as a function of $S / L$ ratio.

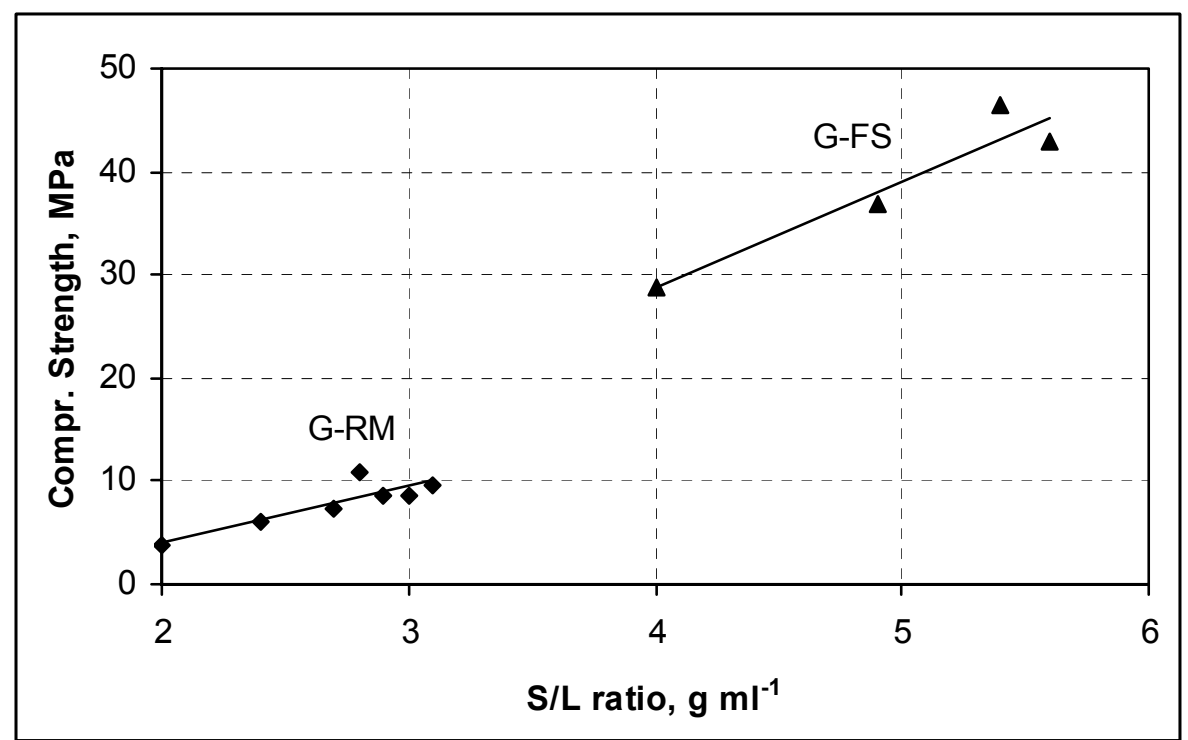

Figure 1. Compressive strength of the red mud/metakaolin- (G-RM) and ferronickel slag- (G$\mathrm{FS}$ ) based inorganic polymeric materials versus $\mathrm{S} / \mathrm{L}$ ratio. Experimental conditions for G-RM: $[\mathrm{NaOH}]=3 \mathrm{M}$ and $[\mathrm{Si}]=3 \mathrm{M}$; for G-FS: $[\mathrm{NaOH}]=10 \mathrm{M}$ and $[\mathrm{Si}]=1.3 \mathrm{M}$ 
As shown in Figure 1, the compressive strength of inorganic polymeric materials of both systems increased almost linearly as $S / L$ ratio was increased. In particular, the red mud/metakaolin-based inorganic polymeric materials developed compressive strength between 3.8 and $9.5 \mathrm{MPa}$, as $\mathrm{S} / \mathrm{L}$ ratio was increased from 2 to $3.1 \mathrm{~g} \mathrm{ml}^{-1}$. The compressive strength of the ferronickel slag-based materials increased from 28.9 to $46.9 \mathrm{MPa}$, as $\mathrm{S} / \mathrm{L}$ ratio was increased from 4 to $5.6 \mathrm{~g} \mathrm{ml}^{-1}$.

The produced inorganic polymeric materials are composite materials consisted of two solid phases, namely the non-dissolved solid particles and the formed geopolymeric binder. Therefore, compressive strength of the materials should be considered as the combination of the strength of the non-dissolved solid particles and the geopolymeric binder. Increase of S/L ratio resulted in increasing the amount of non-dissolved solid particles per volume of produced materials, as is proven by the increase of the materials apparent density. The apparent density of the G-RM materials increased from 1580 to $1838 \mathrm{~kg} \mathrm{~m}^{-3}$ as S/L ratio was increased from 2 to $3.1 \mathrm{~g} \mathrm{ml}^{-1}$, while the apparent density of the G-FS materials increase from 2253 to $2433 \mathrm{~kg} \mathrm{~m}^{-3}$ as S/L ratio was increased from 4 to $5.6 \mathrm{~g} \mathrm{ml}^{-1}$. Besides, increase of S/L ratio resulted in increasing the quantity of the formed geopolymeric binder per volume of produced materials, as is proven by the decrease of the materials porosity. Porosity of materials is proportionally related to the water absorption capacity. The water absorption of the G-RM materials decreased from 4.5 to $2.23 \%$ as S/L ratio was increased from 2 to $3.1 \mathrm{~g}$ $\mathrm{ml}^{-1}$, while the water absorption of the G-FS materials decreased from 4.34 to $1.45 \%$ as S/L was increased from 4 to $5.6 \mathrm{~g} \mathrm{ml}^{-1}$. Concluding, increase of S/L ratio in both studied systems increased the amount of non-dissolved solid particles, as well as of the geopolymeric binder, per volume of produced materials leading to materials with high compressive strength.

In Figure 2, the compressive strength of the produced inorganic polymeric materials is plotted as a function of the $\mathrm{NaOH}$ concentration in the aqueous phase. As it is obvious in Figure 2, the compressive strength of both studied systems inorganic polymeric materials was not a monotonous function of $\mathrm{NaOH}$ concentration. In particular, compressive strength of the red mud/metakaolin-based inorganic polymeric materials increased as $\mathrm{NaOH}$ concentration was increased from $3 \mathrm{M}$ to $8 \mathrm{M}$ and then decreased, as $\mathrm{NaOH}$ concentration was increased up to $10 \mathrm{M}$. Accordingly, compressive strength of the ferronickel slag-based materials increased as $\mathrm{NaOH}$ concentration was increased from $1 \mathrm{M}$ to $7 \mathrm{M}$ and decreased with farther increase of $\mathrm{NaOH}$ concentration until $10 \mathrm{M}$ (Figure 2).

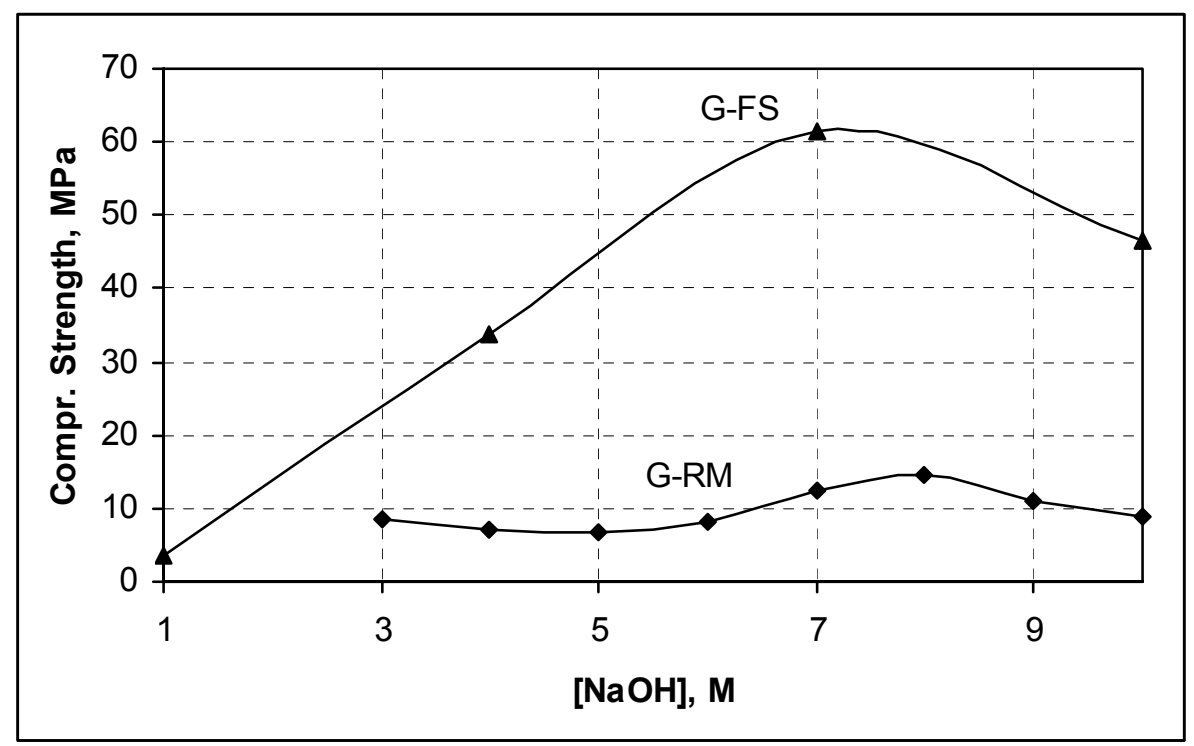

Figure 2. Compressive strength versus $\mathrm{NaOH}$ concentration of the system aqueous phase. Experimental conditions for G-RM: $S / L=2.9 \mathrm{~g} \mathrm{ml}^{-1}$ and $[\mathrm{Si}]=3 \mathrm{M}$; for $\mathrm{G}-\mathrm{FS}$ : $\mathrm{S} / \mathrm{L}=5.4 \mathrm{~g} \mathrm{ml}^{-1}$ and $[\mathrm{Si}]=1.3 \mathrm{M}$ 
Increase of the $\mathrm{NaOH}$ concentration accelerates directly the dissolution rates of silicate and aluminosilicate phases of the system solid materials, improving the effectiveness of the geopolymerization process (Panias et al., 2007). Increased Si and Al contents in the aqueous phase of the geopolymeric system are essential for initiating the oligomers formation and in turn, their polycondensation. Thus, the increase of $\mathrm{NaOH}$ concentration affects positively the mechanical strength of the obtained materials. However, this is not in accordance with the experimental results shown in Figure 2. Although the formation of polymeric species is enhanced under increased $\mathrm{Si}$ and $\mathrm{Al}$ contents in the system aqueous phase, it is inhibited under extremely high $\mathrm{NaOH}$ concentrations. Under such conditions, the $\mathrm{SiO}_{2}$ to $\mathrm{Na}_{2} \mathrm{O}$ ratio in the aqueous phase of the system decreases, rendering the monosilicate and oligomeric species predominant in favour of polymers and complex structures that promote the geopolymerization process (Panias et al., 2007). As a result, the compressive strength of the produced materials decreases.

Concluding, there is an optimum value for the $\mathrm{NaOH}$ concentration for the studied systems, up to which the compressive strength of the obtained materials is decreased. Generally, for each geopolymeric system there is an optimum value of $\mathrm{NaOH}$ concentration that leads to materials with high mechanical strength (Chindaprasirt et al., 2008; Komnitsas et al., 2008). For the G-RM system currently studied, this value was set at $8 \mathrm{M}$, where the produced materials reached a compressive strength of $14.6 \mathrm{MPa}$. For the investigated G-FS system, the optimum $\mathrm{NaOH}$ concentration was set at $7 \mathrm{M}$, for which the compressive strength of the obtained materials was equal to $61.6 \mathrm{MPa}$.

In Figure 3, the compressive strength of both systems inorganic polymeric materials is plotted versus silicon concentration in the system aqueous phase. According to Figure 3, compressive strength of the red mud/metakaolin-based inorganic polymeric materials (G-RM) increased almost linearly as silicon concentration was increased from $3 \mathrm{M}$ to $5.5 \mathrm{M}$, where it reached the value of 21.3 $\mathrm{MPa}$. Compressive strength of the ferronickel slag-based materials (G-FS) followed similar behaviour and increased with the increase of silicon concentration from $0.7 \mathrm{M}$ to $4 \mathrm{M}$, reaching the value of $118.1 \mathrm{MPa}$ for the highest experimentally investigated silicon concentration (Figure 3).

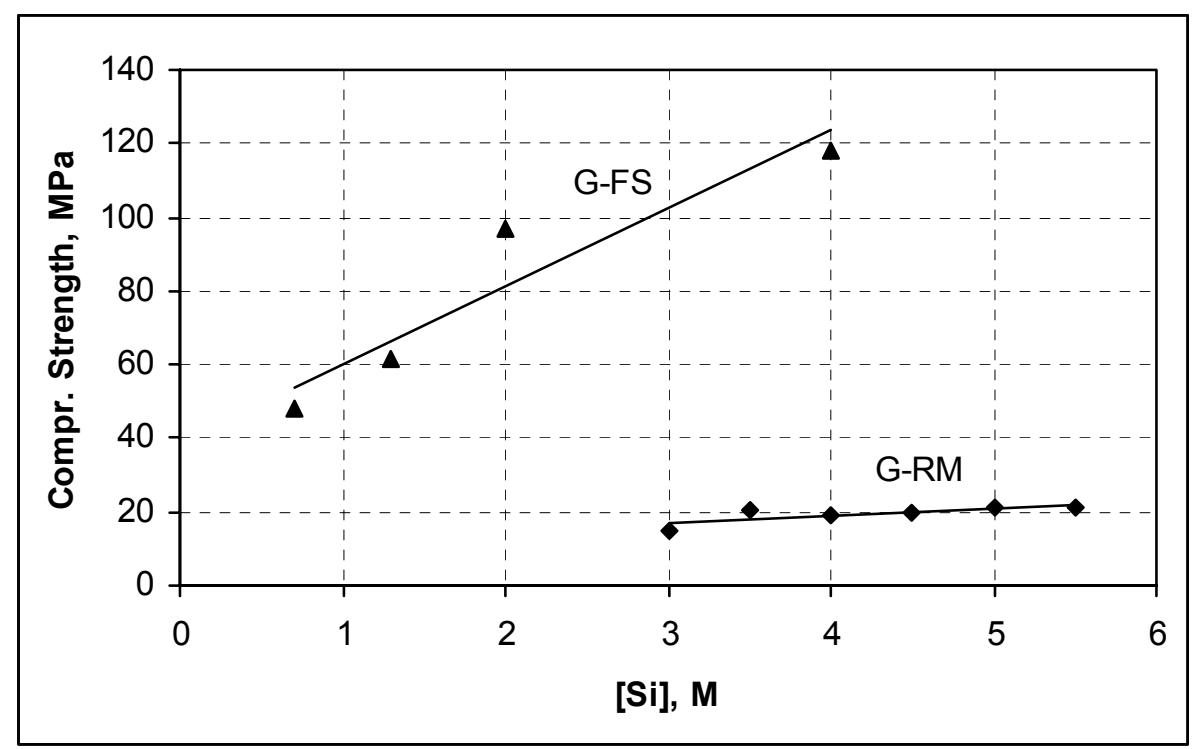

Figure 3. Compressive strength versus $\mathrm{Si}$ concentration in the system aqueous phase.

Experimental conditions for G-RM: S/L $=2.9 \mathrm{~g} \mathrm{ml}^{-1}$ and $[\mathrm{NaOH}]=8 \mathrm{M}$; for G-FS:

$$
\mathrm{S} / \mathrm{L}=5.4 \mathrm{~g} \mathrm{ml}^{-1} \text { and }[\mathrm{NaOH}]=7 \mathrm{M}
$$

Under constant $\mathrm{NaOH}$ concentration, continuous addition of soluble silicates increases the $\mathrm{SiO}_{2}$ to $\mathrm{Na}_{2} \mathrm{O}$ ratio in the aqueous phase of the system. This increase shifts gradually the chemical system to the formation of silicate species with complex polymeric structures giving rise to the development of a three-dimensional polymeric framework, which is related to 
materials of high mechanical strength (Panias et al., 2007). However, the beneficial effect of the increased $\mathrm{SiO}_{2}$ to $\mathrm{Na}_{2} \mathrm{O}$ ratio on the mechanical properties of the produced materials is limited under high $\mathrm{SiO}_{2}$ to $\mathrm{Na}_{2} \mathrm{O}$ ratios, which affect the viscosity of the produced pastes causing obvious defects on the produced materials. For the G-RM and the G-FS systems studied in the current work, the limited value of silicon concentration was determined at $3.5 \mathrm{M}$ and $4 \mathrm{M}$, respectively.

The red mud/metakaolin-based inorganic polymeric materials produced under synthesis conditions $\mathrm{S} / \mathrm{L}=2.9 \mathrm{~g} \mathrm{ml}^{-1},[\mathrm{NaOH}]=8 \mathrm{M}$ and $[\mathrm{Si}]=3.5 \mathrm{M}$, which were determined as optimum for the currently studied G-RM system, developed compressive strength equal to $20.5 \mathrm{MPa}$ and presented water absorption equal to $1.9 \%$. The ferronickel slag-based materials obtained under the synthesis conditions $\mathrm{S} / \mathrm{L}=5.4 \mathrm{~g} \mathrm{ml}^{-1},[\mathrm{NaOH}]=7 \mathrm{M}$ and $[\mathrm{Si}]=4$ $\mathrm{M}$ proved as optimum for the G-FS system in this work, reached a compressive strength of 118.1 $\mathrm{MPa}$ and presented water absorption equal to $0.8 \%$. Comparing these values of compressive strength and water absorption with the relevant of commercial construction and building materials (Giannopoulou and Panias, 2008), it is concluded that the produced inorganic polymeric materials may find important applications in the industrial sectors of construction and building materials.

\subsection{Structure of inorganic polymeric materials}

The structural transformations occurred during the geopolymerization of red mud and ferronickel slag, are investigated according to XRD and FTIR analysis of the produced inorganic polymeric materials. Figure 4(a) presents the XRD diagrams of red mud (RM), metakaolin (MK) and the red mud/metakaoline-based inorganic polymeric materials (OG-RM) produced under optimum synthesis conditions $\left(\mathrm{S} / \mathrm{L}=2.9 \mathrm{~g} \mathrm{ml}^{-1},[\mathrm{NaOH}]=8 \mathrm{M}\right.$ and $[\mathrm{Si}]=3.5$ $M)$, while in Figure 4(b) the XRD diagrams of ferronickel slag (FS) and the ferronickel slagbased inorganic polymeric materials (OG-FS) produced under optimum synthesis conditions $\left(\mathrm{S} / \mathrm{L}=5.4 \mathrm{~g} \mathrm{ml}^{-1},[\mathrm{NaOH}]=7 \mathrm{M}\right.$ and $\left.[\mathrm{Si}]=4 \mathrm{M}\right)$, are shown.

Comparing the XRD diagrams presented in Figure 4(a), it is obvious that the main crystalline phases of red mud were also detected in the XRD diagram of the obtained inorganic polymeric materials (OG-RM), indicating the existence of non-dissolved solid particles of red mud in the produced materials. In opposite, the crystalline Al-Si phases detected in the XRD diagram of metakaolin (MK), as well as the amorphous phase registered between $2 \theta \sim 18^{\circ}$ and $30^{\circ}$ in the same XRD diagram, are totally dissolved in the produced inorganic polymeric materials. Moreover, a new crystalline phase of Al-Si composition is detected in the XRD diagram of the red mud/metakaolin-based inorganic polymeric materials at $2 \theta \sim 18^{\circ}$. Similar observations derived from the comparison between the XRD diagrams of the ferronickel slag and the slag-based inorganic polymeric materials (Fig. 4b). In particular, magnetite, which consist the only crystalline phase originally occurred in the ferronickel slag (FS), was also detected in the obtained inorganic polymeric materials (OG-FS) indicating the presence of non-dissolved slag particles in the final materials. Moreover, the intensity of the broad hump that was registered between $2 \theta=20^{\circ}$ and $40^{\circ}$ in the slag XRD diagram and attributed to the amorphous phase of the ferronickel slag, decreased in the XRD diagram of the slag-based inorganic polymeric materials indicating partial dissolution of this phase in the obtained materials. Finally, new amorphous phases registered at around $2 \theta=5^{\circ}$ were appeared in the XRD diagram of the slag-based inorganic polymeric materials. These new phases were assigned to aluminum silicate zeolites and indicated the formation of an aluminosilicate gel phase in the obtained materials.

The structural transformations of solid materials of both investigated systems (G-RM and GFS) that took place in the produced inorganic polymeric materials were also well recognized according to FTIR spectroscopy. According to Figure 5(a), where the FTIR spectra of the ferronickel slag (FS) and the slag-based inorganic polymeric materials synthesized under optimum conditions (OG-FS) are shown, the main differences observed between the two FTIR spectra are summarized in three areas of wavenumbers. 


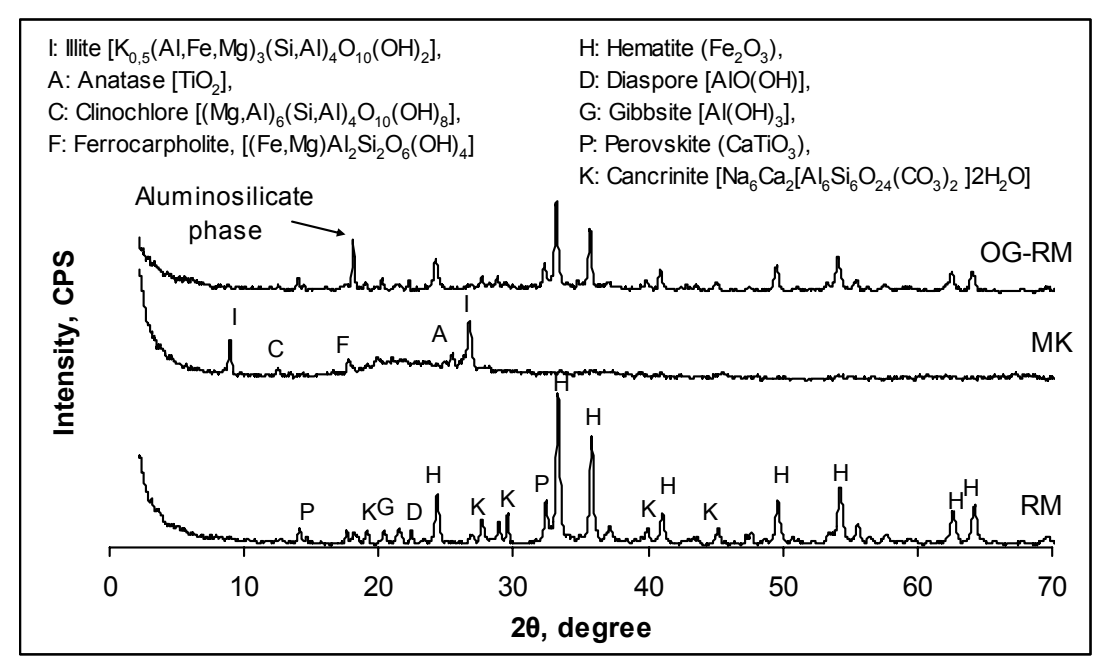

(a)

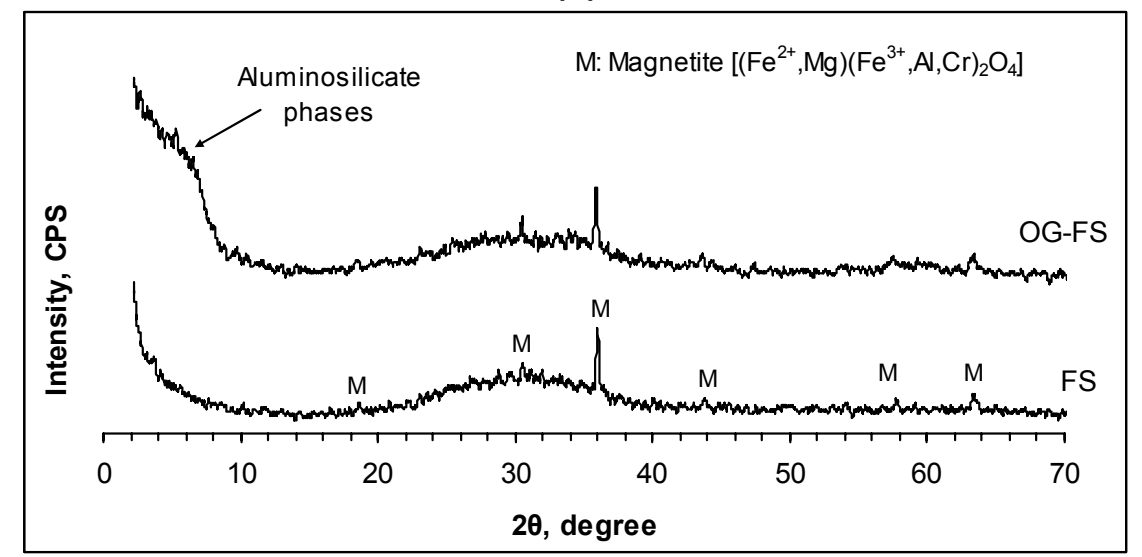

(b)

Figure 4. X-ray diffractograms of (a) red mud (RM), metakaolin (MK) and red mud/metakaolinbased inorganic polymeric materials (OG-RM) and (b) ferronickel slag (FS) and ferronickel slag-based inorganic polymeric materials (OG-FS)

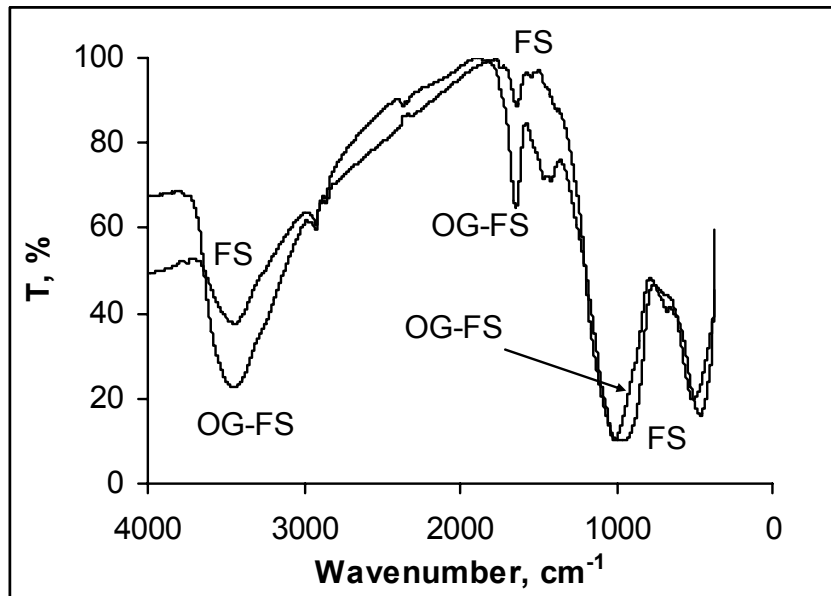

(a)

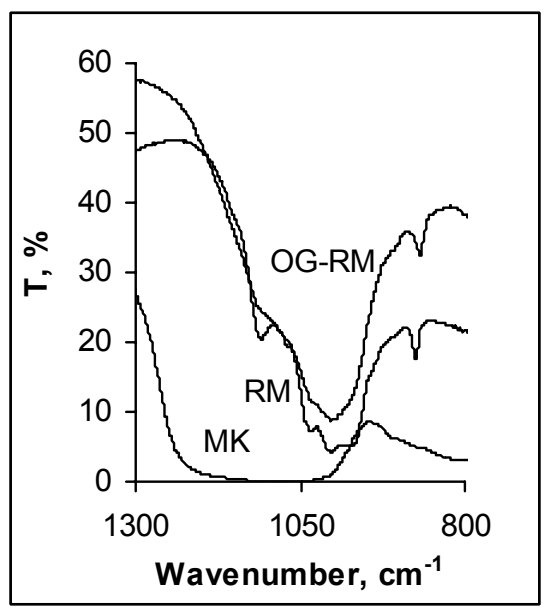

(b)

Figure 5. FTIR spectra of (a) ferronickel slag (FS) and the slag-based inorganic polymeric materials (OG-FS) and (b) red mud (RM), metakaolin (MK) and the red mud/metakaolinbased inorganic polymeric materials (OG-RM)

The first area was located at wavenumbers higher than $1600 \mathrm{~cm}^{-1}$, where the appeared bands were assigned to stretching $(-\mathrm{OH})$ and bending $(\mathrm{H}-\mathrm{O}-\mathrm{H})$ vibrations of bound water molecules. 
The peak intention of these bands was greater in the FTIR spectrum of the inorganic polymer indicating higher degree of bound water molecules in the obtained materials (Bakharev, 2005; Fernadez and Palomo, 2005). The second area appeared at around $1400 \mathrm{~cm}^{-1}$, where a broad band attributed to stretching vibrations of the $\mathrm{O}-\mathrm{C}-\mathrm{O}$ bond was detected indicating carbonation of the produced materials (Panias et al., 2007). Finally, the third area was placed at wavenumbers lower than $1100 \mathrm{~cm}^{-1}$, where the bands assigned to asymmetric stretching vibrations of $\mathrm{Si}-\mathrm{O}-\mathrm{Si}$ bonds, symmetric stretching vibrations of $T-\mathrm{O}-\mathrm{Si}(T=\mathrm{Si}$ or $\mathrm{Al})$ bonds and symmetric bending vibrations of $\mathrm{Si}-\mathrm{O}-\mathrm{Si}$ and $\mathrm{O}-\mathrm{Si}-\mathrm{O}$ bonds were appeared.

Especially, the differences appeared in this third area of wavenumbers are strongly related to the geopolymerization fingerprint, as they confirm the dissolution of the raw solid materials during geopolymerization and the formation of new amorphous aluminosilicate phases in the produced materials (Lee and Van Deventer, 2002; Fernadez and Palomo, 2005; Maragkos et al., 2008). As it is obvious in Figure 5(a), the broad band detected in the FTIR spectrum of slag at around $990 \mathrm{~cm}^{-1}$ has become sharper and was shifted towards higher wavenumbers in the FTIR spectrum of the slag-based inorganic polymer, confirming the formation of a new aluminosilicate phase. The same observation is also clear in Figure 5(b), where the FTIR spectra of red mud (RM), metakaolin (MK) and the red mud/metakaolin-based inorganic polymeric materials produced under the optimum synthesis conditions raised in this work (OG-RM) are given in the area of wavenumbers from 1300 to $800 \mathrm{~cm}^{-1}$. The broad band detected in the FTIR spectrum of metakaolin at around $1100 \mathrm{~cm}^{-1}$ became sharper and shifted towards lower wavenumbers in the FTIR spectrum of the OR-RM materials, indicating destruction of the metakaolin aluminosilicate phases and formation of new Al-Si phases in the obtained inorganic polymeric material.

The formation of the above mentioned new amorphous aluminosilicate phase in the inorganic polymeric materials was also confirmed by the SEM study of the materials produced under the optimum synthesis conditions concluded in the current study. In Figure 6, SEM micrographs from the fracture surface formed during the compressive strength tests present the typical structure of the produced inorganic polymeric materials.

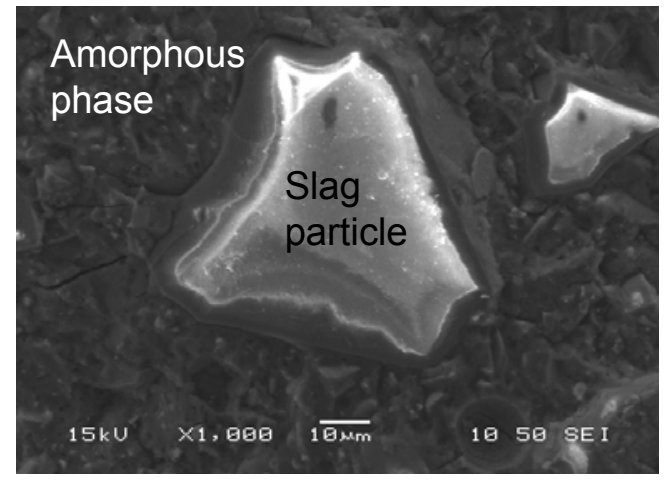

(a)

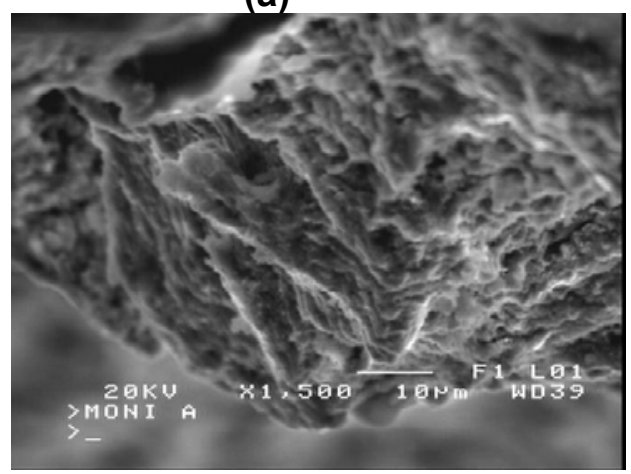

(c)

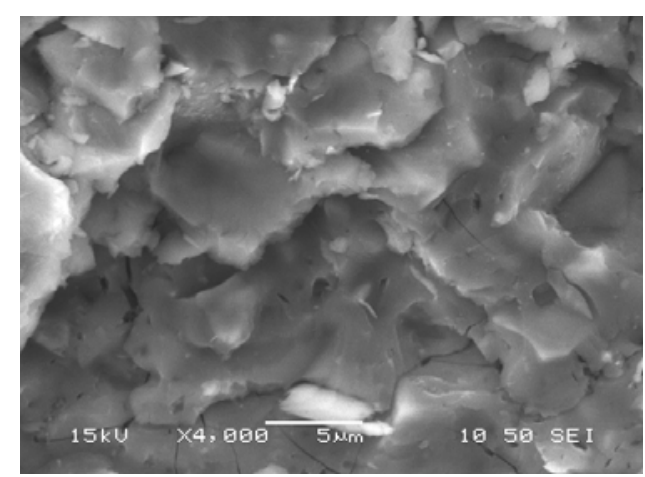

(b)

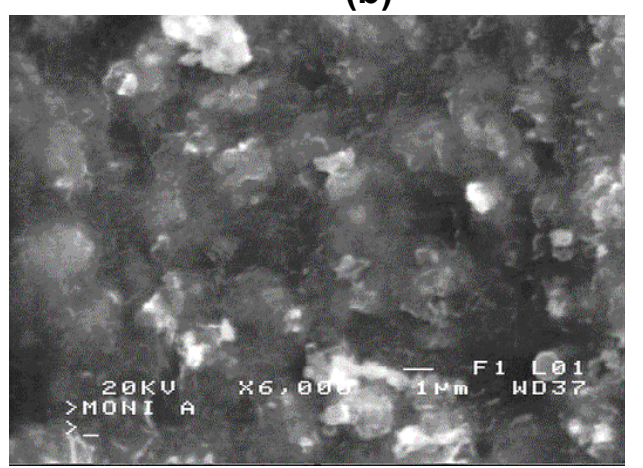

(d)

Figure 6. SEM micrographs of (a) and (b) the ferronickel slag- and (c) and (d) red $\mathrm{mud} /$ metakaolin-based inorganic polymeric materials 
As shown in Figures 6 (a) and (c), the non-dissolved particles of ferronickel slag and red mud, respectively, are well bonded in the amorphous gel phase of the obtained materials. The cracks formed around the borders of non-dissolved particles and in the gel phase surrounding the particles (Fig. 6a) indicated that the mechanical strength of the geopolymeric binder was lower than that of the non-dissolved particles. Generally, the interface between the nondissolved particles and the gel phase is the most sensitive for the materials failure during the compressive strength tests. The geopolymeric binder of the ferronickel slag- and the red $\mathrm{mud} /$ metakaolin- based materials is shown in Figures 6(b) and (d), respectively. According to the EDS analysis performed in specific areas of the SEM micrographs presented in Fig. 6(b) and (d), the geopolymeric binder is of aluminosilicate composition with Si/AI molar ratio equal to 5 and 2.5 , respectively.

The inorganic polymeric materials produced under optimum synthesis conditions for each system investigated in this work, developed submicro- or nano- porosity; although such porosity was not possible to be observed according to SEM analysis, it was experimentally confirmed by the low water adsorption (WA) of these materials, as seen in section 3.1.

\section{CONCLUSIONS}

In this work, the geopolymerization of the red mud generated in primary aluminium production and the slag generated in ferronickel production were investigated. The initial solid to liquid ratio of the geopolymeric system, as well as the concentrations of sodium hydroxide and silicon in the aqueous phase of the system, were proved as crucial synthesis parameters for the mechanical strength developed the obtained inorganic polymeric materials, affecting directly all stages of the geopolymerization process.

Under the optimum synthesis conditions defined in this work, the red mud/metakaolin-based inorganic polymeric materials developed compressive strength equal to $20.5 \mathrm{MPa}$ and presented $1.9 \%$ water absorption, while the ferronickel slag-based inorganic polymeric materials presented compressive strength higher than $110 \mathrm{MPa}$ and water absorption lower than $1 \%$. These properties make of interest the utilization of the red mud and the ferronickel slag in the construction and building materials industries.

The excellent physical and mechanical properties of the produced inorganic polymeric materials were attributed to the formation of an amorphous aluminosilicate gel phase, in which the non-dissolved particles of the raw solid materials were well bonded. The formed amorphous Al-Si phase was revealed according to XRD and FTIR analysis and detected through SEM analysis of the obtained materials.

\section{REFERENCES}

Bakharev T., (2005), Geopolymeric materials prepared using Class F fly ash and elevated temperature curing, Cement and Concrete Research, 35(6), 1224-1232.

Bankowski P., Zou L. and Hodges R., (2004), Reduction of metal leaching in brown coal fly ash using geopolymers, Journal of Hazardous Materials, 114(1-3), 59-67.

Cheng T.W. and Chiu J.P., (2003), Fire-resistant geopolymer produced by granulated blast furnace slag, Minerals Engineering, 16(3), 205-210.

Chindaprasirt P., Jaturapitakkul C., Chalee W., Rattanasak U., (2008), Comparative study on the characteristics of fly ash and bottom ash geopolymers, Waste Management, 29(2), 539-543.

Davidovits J., (1999), Chemistry of geopolymeric systems - Terminology, in: J. Davidovits, R. Davidovits C.J., (Eds.), Proceedings of the 2nd International Conference Geopolymere '99, Saint Qunentin, France, June 30-July 2, 1999, 9-39.

European Commission. (1996), "Council Directive 96/61/EC of 24 September 1996 concerning integrated pollution prevention and control", Official Journal, L 257 10/10/1996, 0026 - 0040.

Fernandez-Jimenez A. and Palomo A., (2005), Composition and microstructure of alkali activated fly ash binder: Effect of the activator, Cement and Concrete Research, 35(10), 1984-1992.

Giannopoulou I. and Panias D., (2008), Geopolymeric building materials from solid aluminosilicate by-products, in: Technical Chamber of Greece (Ed.), Proceedings of the 1st Panhellenic Conference of Building Materials, Athens, Greece, May 21-23, 2008, 1733-1743 (in Greek). 
Komnitsas K., Zaharaki D. and Perdikatsis V., (2008), Effect of synthesis parameters on the compressive strength of low-calcium ferronickel slag inorganic polymers, Journal of Hazardous Materials, 161(2-3), 760-768.

Lee W.K.W. and Van Deventer J.S.J., (2002), Structural reorganization of class F fly ash in alkaline silicate solutions, Colloids and Surfaces A: Physicochemical and Engineering Aspects, 211(1), 49-66.

Maragkos I., Giannopoulou I. and Panias D., (2008), Synthesis of ferronickel slag-based geopolymers, Minerals Engineering, 22(2), 196-203.

Palomo A., Grutzeck M.W. and Blanco M.T., (1999), Alkali-activated fly ashes: A cement for the future, Cement and Concrete Research, 29(8), 1323-1329.

Panias D., Giannopoulou I. and Perraki Th., (2007), Effect of synthesis parameters on the mechanical properties of fly ash-based geopolymers, Colloids and Surfaces $A$ : Physicochemical and Engineering Aspects, 301(1-3), 246-254.

Swanepoel J.C. and Strydom C.A., (2002), Utilization of fly ash in a geopolymeric material, Applied Geochemistry, 17(8), 1143-1148.

Van Deventer, J.G.S, Van Deventer and J.S.J, Lukey G.C., (2002), The effect of composition and temperature on the properties of fly ash- and kaolinite-based geopolymers, Chemical Engineering Journal, 89(1-3), 63-73.

Van Jaarsveld J.G.S., Van Deventer J.S.J. and Schwartzman A., (1999), The potential use of geopolymeric materials to immobilise toxic materials: Part II. Material and leaching characteristics, Minerals Engineering, 12(1), 75-91.

Xu J.Z., Zhou Y.L., Chang Q. and Qu H.Q., (2006), Study on the factors of affecting the immobilization of heavy metals in fly ash-based geopolymers, Materials Letters, 60(6), 820822. 